\title{
Relatively low and moderate pre-fracture serum 25-hydroxyvitamin $D$ levels associated with the highest survival in elderly hip fracture patients in Finland: a minimum 3-year follow-up
}

\author{
I. Nurmi-Lüthje ${ }^{1}$ (D) R. Tiihonen ${ }^{2} \cdot$ E-L. Paattiniemi ${ }^{3} \cdot$ H. Sarkkinen ${ }^{3} \cdot$ H. Naboulsi ${ }^{4} \cdot$ S. Pigg ${ }^{5} \cdot$ J-P. Kaukonen $^{6}$. \\ M. Kataja ${ }^{7}$ P. Lüthje ${ }^{8}$
}

Received: 19 April 2021 / Accepted: 5 August 2021 / Published online: 30 September 2021

(c) International Osteoporosis Foundation and National Osteoporosis Foundation 2021, corrected publication 2021

\begin{abstract}
Summary The association between serum 25 -hydroxyvitamin $\mathrm{D}$ level and post-fracture mortality indicates beneficial relatively high serum 25-hydroxyvitamin D concentrations. A 1-year cohort study on 245 hip fracture patients in Finland indicated the lowest 3-year mortality and highest survival among patients with serum 25-hydroxyvitamin D level of 50-74 nmol/L. Purpose To explore pre-fracture serum 25-hydroxyvitamin D level as a factor associated with post-fracture survival among a cohort of hip fracture patients in Finland.

Methods A prospectively collected cohort of hip fracture patients ( $n=245,70 \%$ women) from two hospitals was followed for 3.2 post-hip fracture years. Serum 25 -hydroxyvitamin $D$ was measured in admission to the hospital and classified: $<50$, $50-74,75-99$, and $\geq 100 \mathrm{nmol} / \mathrm{L}$. Survival was analyzed with a Bayesian multivariate model. Relative survival was explored with the life table method according to serum 25 -hydroxyvitamin D. Mortality according to serum 25 -hydroxyvitamin D level and to the hospital was calculated.

Results Mortality in the patients with serum 25-hydroxyvitamin D level of 50-74 nmol/L was significantly lower than in all other patients together at every post-fracture year. The most important factors for survival were age under 85 years; living in an actual/private home; serum 25 -hydroxyvitamin D level of $50-74 \mathrm{nmol} / \mathrm{L}$, followed by $75-99 \mathrm{nmol} / \mathrm{L}$; ASA classes $1-2$ and 3; and female sex. The mean age of patients with serum 25-hydroxyvitamin D level of 50-99 nmol/L was significantly higher than in other levels. Relative survival was highest in men, women, and patients in hospital B with serum 25-hydroxyvitamin D level of 50-74 nmol.

Conclusion The highest 3-year survival and the lowest mortality in this cohort appeared in patients with pre-fracture serum 25-hydroxyvitamin D level of 50-74 $\mathrm{nmol} / \mathrm{L}$. This result differs from similar studies and is lower than the recommended level of 25-hydroxyvitamin D among hip fracture patients. The results should be examined in future research with larger data.
\end{abstract}

Keywords Hip fracture $\cdot$ Prospective cohort $\cdot$ Serum 25-hydroxyvitamin D $\cdot$ Mortality $\cdot$ Survival

I. Nurmi-Lüthje

ilona.nurmi@pp.inet.fi

1 Department of Public Health, Helsinki University, Mannerheimintie 172, FI-00300 Helsinki, Finland

2 Department of Orthopedics and Traumatology, Päijät-Häme Central Hospital, Keskussairaalankatu 7, FI-15850 Lahti, Finland

3 Centre for Laboratory Services, Päijät-Häme Social and Health Care Group, Keskussairaalankatu 7, FI-15850 Lahti, Finland
4 Joint Authority for Päijät-Häme Social and Health Care Services, Päijät-Häme Social and Health Care Group, Keskussairaalankatu 7, FI-15850 Lahti, Finland

5 Kouvola Health Center, Marjoniementie 10, FI-45100 Kouvola, Finland

6 Terveystalo Lahti, Aleksanterinkatu 11-13, FI-15110 Lahti, Finland

7 National Institute for Health and Welfare, Mannerheimintie 166, FI-0027 Helsinki, Finland

8 North Kymi Hospital, FI-45750 Kuusankoski, Finland 


\section{Introduction}

Nearly all patients with a low-energy hip fracture need operative treatment and have high postoperative morbidity and mortality. The mortality is elevated during the first postoperative year, and it remains high for the following years [1]. Many studies reported that mortality among elderly hip fracture patients is higher than that of the age-adjusted general population and also higher among men than women [2-4]. Post-hip-fracture mortality is $7-8 \%$ at 30 days $[5,6]$, $14-34.8 \%$ at 1 year [7, 8], and $32-56 \%$ at 5 years $[9,10]$.

Some studies among older populations have shown that a low concentration of serum hydroxyvitamin D (S-25OHD) is associated with an increased risk of death from all causes. According to a European consortium of eight prospective studies, including seven general population cohorts, there was an association between low serum 25-hydroxyvitamin $\mathrm{D}$ level $(<50 \mathrm{nmol} / \mathrm{L})$ and increased risk of all-cause mortality compared to persons with a level of 75-99 nmol/L [11].

A review of several studies showed that humans are vitamin D replete when their serum 25 -hydroxyvitamin D levels are $\geq 50 \mathrm{nmol} / \mathrm{L}$ [12]. Recently, experts from different specialties around the world published their consensus recommendations on the prevention and management of nutritional rickets in population [13]. They defined vitamin D sufficiency as serum 25-hydroxyvitamin D levels above $50 \mathrm{nmol} / \mathrm{L}$, insufficiency between 30 and $50 \mathrm{nmol} / \mathrm{L}$, and deficiency below $30 \mathrm{nmol} / \mathrm{L}$. According to the Institute of Medicine [14] and Endocrine Society [15] levels of $\geq 50 \mathrm{nmol} / \mathrm{L}$ can be achieved in nearly all adults by taking the daily allowance for vitamin D (600 IU/day for adults $<70$ years old and 800 IU/day for adults $\geq 70$ years old). In Nordic countries, including Finland, the present vitamin $\mathrm{D}$ recommendation for individuals $<75$ years is $600 \mathrm{IU} /$ day and adults $\geq 75$ years $800 \mathrm{IU} /$ day [16].

Low vitamin $\mathrm{D}(<50 \mathrm{nmol} / \mathrm{L})$ at admission for hip fracture increased the risk of delirium, new hip fracture, and medical readmission, but not surgical complications in 1122 patients at Oslo University Hospital, Norway [17]. On the other hand, persons with higher levels ( $\geq 75 \mathrm{nmol} / \mathrm{L})$ who had prior falls had no benefit in lower extremity function and were associated with an increased risk of falls [18].

In 2003 and 2004, we studied the serum 25-hydroxyvitamin D levels in 221 White Finnish-born patients with an acute low-energy hip fracture in two hospitals, responsible for an area comprising a total of 300,000 inhabitants (5.7\% of the Finnish population) in southeastern Finland [19]. The survival analysis of that data indicated excess mortality for at least 11 years after hip fracture, compared with the general population. Survival was highest among patients with a pre-fracture serum 25-hydroxyvitamin D level of $\geq 50 \mathrm{nmol} / \mathrm{L}$ [10].
In the present study, with the same setting as in the previous study [19], our aim was to explore the potential role of the pre-fracture vitamin D concentration as a factor associated with post-fracture survival among hip fracture patients and to compare the results with those found in our previous study [10]. In both the previous and present data, the serum 25-hydroxyvitamin concentration was measured in admission to the hospital for hip fracture $[19,20]$.

The data in the present study were prospectively collected for 1 year, and the survival was followed for 38.5 months (3.2 years).

\section{Patients and methods}

In the primary study [20], we prospectively registered a total of 245 consecutive white native Finnish-born patients with an acute low-energy hip fracture at Päijät-Häme Central Hospital (hospital A) and North Kymi Hospital (hospital B), both located in southern Finland $\left(61^{\circ} \mathrm{N}\right)$. High-energy and pathological hip fractures were excluded. The data were collected from 15 October 2015 to 15 October 2016 (1 year). In admission to the hospital, trained nurses collected the data on the pre-fracture use of vitamin D and calcium supplements by asking each patient or his/her representative (relative or carer) whether he/she used calcium and/or vitamin D supplementation on a daily basis before the injury. The collection of the basic data on patients has been described previously [20].

\section{Laboratory methods}

Serum samples were collected after patients arrived at hospitals due to the index fracture. The samples were centrifuged at $2000 \mathrm{~g}$ for $10 \mathrm{~min}$ and frozen as soon as possible. The frozen samples were transferred from hospital B to hospital A, where all the samples were stored at $-70{ }^{\circ} \mathrm{C}$ until analyzed in batches. Serum assays were performed in cobas 8000 modular analyzer series (Roche Diagnostic $\mathrm{GmbH}$, Mannheim, Germany). S-25OHD was measured using a 25-hydroxyvitamin D electrochemiluminescence binding assay (Roche Diagnostic GmbH, Mannheim, Germany). The assay employs a vitamin $\mathrm{D}$ binding protein to bind vitamin $\mathrm{D}_{3}(25-\mathrm{OH})$ and vitamin $\mathrm{D}_{2}(25-\mathrm{OH})$. The measurement range is $7.5-175 \mathrm{nmol} / \mathrm{L}$, and the reference range is $>50 \mathrm{nmol} / \mathrm{L}$. The method has been standardized against liquid chromatography-tandem mass spectrometry [21] which, in turn, has been standardized to the NIST standard [22]. At the normal range (mean $70.8 \mathrm{nmol} / \mathrm{L}$ ), repeatability and intermediate precision of the test are 3.9 and $6.5 \%$, respectively. Cross-reactivity for 25 -hydroxyvitamin $\mathrm{D}_{3}$ is $100 \%$ and for 25 -hydroxyvitamin $\mathrm{D}_{2}, 92 \%$. Cross-reactivity for 25 -hydroxyvitamin $\mathrm{D}_{3}$ is $100 \%$ both in the current assay 
(Roche Diagnostics) and in the radioimmunoassay (IDS) used in the previous study [10] and for 25-hydroxyvitamin $\mathrm{D}_{2}, 92 \%$ and $75 \%$, respectively. According to information provided by the manufacturers, there is no significant difference in cross-reactivity for 24,25 -dihydroxyvitamin $\mathrm{D}_{3}$, cholecalciferol $\mathrm{D}_{3}$, and ergocalciferol $\mathrm{D}_{2}$ between the assays.

For the present study, serum 25-hydroxyvitamin D levels were redistributed as follows: $<50 \mathrm{nmol} / \mathrm{L}, 50-74 \mathrm{nmol} / \mathrm{L}$, $75-99 \mathrm{nmol} / \mathrm{L}$, and $\geq 100 \mathrm{nmol} / \mathrm{L}$. The preoperative ASA physical grading score measuring patient's preoperative health status and perioperative risk was determined for each patient by the attending anesthesiologist as follows: class 1 , a normal healthy patient; class 2 , a patient with mild systemic disease; class 3, a patient with severe systemic disease; class 4 , a patient with severe systemic disease that is a constant threat to life; and class 5, a moribund patient who is not expected to survive without operation [23]. In the present study, ASA classes 1 and 2 were combined. There were no patients in ASA class 5 .

\section{Statistical methods}

Differences between two groups were tested with chisquared $\left(\chi^{2}\right)$ test, Fisher's exact test, or Wilcoxon rank test and between three groups with the Kruskal-Wallis test. Differences in mean values between groups were tested using a two-way analysis of variance (ANOVA).

Survival was analyzed with univariate and multivariate analyses. In the univariate analysis, the odds ratios of survival were calculated for each class of the variable and compared with each other within the variable. Statistical dependency within each variable was analyzed using the chi-squared $\left(\chi^{2}\right)$ test or Wilcoxon rank test.

Multivariate analysis was performed using an optimizing step-wise procedure based on the Bayesian approach [10]. The optimizing procedure has been developed mainly for categorized variables and does not need a perfect variable matrix. Following a heuristic approach, the procedure selects the combination of variables that best explains the selected outcome variable. The Bayesian approach is applied by calculating posterior probability ratios for each combination. The aim is to find an optimal set of variables that provides a better explanation than all the variables together. The relationship between the true positives and true negatives was graphically described as a receiving operating characteristic curve (ROC). The area under the curve (AUC) approximately describes the explanatory power of the model [24, 25].

Survival compared to the reference population was analyzed using the life table method [26]. In this method, the observed survival rates of the study groups are compared with survival rates based on sex- and age-specific life tables for the entire Finnish population of the same age and same time period (reference population). The calculated survival of the reference population is 1.00 . If the survival curve of the study group remains below the survival of the reference population, there is excess mortality in the group. We analyzed the relative survival according to sex and to pre-fracture serum 25-hydroxyvitamin D level. Sub-analysis on the relative survival according to serum 25-hydroxyvitamin D was performed among patients in hospital B.

The dates of deaths were collected from the nationwide administrative register, the Causes-of-Death Register of Statistics Finland, using the unique personal identification number of the patients. The last date of collection was October 15, 2019. The follow-up time of mortality was from October 15, 2015, to December 30, 2019. Thus, every patient was followed for 38.5 months (3.2 years). The first SARS-CoV-2 virus infection in Finland was reported on January 19, 2020.

The study protocol was approved by the Ethics Committee of Surgery at the Hospital District of Helsinki and Uusimaa in Finland. The work has been carried out in accordance with the Code of Ethics of the World Medical Association (Declaration of Helsinki) for experiments involving humans.

\section{Results}

In the primary study, a total of 245 patients (171 (70\%) women and $74(30 \%)$ men) with an acute hip fracture were enrolled: 156 in hospital A (68\% women) and 89 (73\% women) in hospital B. The mean age of the patients at the time of index fracture was 80.3 (SD10.4), in women 81.3 years (SD 9.5) and in men 78 years (SD 11.9) (n.s.) [20].

Of the index hip fractures, $59 \%$ were femoral neck fractures, $34 \%$ trochanteric fractures, and $7 \%$ subtrochanteric fractures [20]. All patients were treated operatively according to standard procedures: femoral neck fractures with screws or a dynamic hip screw, with hemiarthroplasty or total hip replacement; trochanteric fractures were treated with a dynamic hip screw or intramedullary nail; and subtrochanteric fractures were treated with an intramedullary nail.

There were no differences in the place of residence of the patients between the hospitals: $177(72 \%)$ of the patients were living in actual/private home; $25(10 \%)$ were living in a residential home; 37 (15\%) were living in a residential home with $24 \mathrm{~h}$ assistance; and $6(3 \%)$ were living in a hospital or other institution (n.s.) [20].

A slight difference was found in ASA classes between the hospitals (Table 1). There was no difference between sexes in the distribution of ASA classes 1-2, 3, and 4 $(\mathrm{Wx}=-0.073$, n.s. $)$. 
Table 1 S-25OHD concentration (nmol/L) and cumulative mortality at 1, 2, 4, 12, 24, and 36 post-fracture months according to hospital

\begin{tabular}{|c|c|c|c|c|c|c|c|}
\hline & Hospital A $(n=156)$ & & Hospital $\mathrm{B}^{\mathrm{a}}(n=88)$ & & Total $(n=244)$ & & Statistic \\
\hline $\mathrm{S}-25 \mathrm{OHD}(\mathrm{nmol} / \mathrm{L})$ & $n$ & $\%$ & $n$ & $\%$ & $n$ & $\%$ & \\
\hline$<50$ & 23 & 14.7 & 32 & 36.4 & 55 & 22.5 & \\
\hline $50-74.9$ & 47 & 30.1 & 28 & 31.8 & 75 & 30.7 & \\
\hline $75-99.9$ & 48 & 30.8 & 21 & 23.9 & 69 & 28.3 & \\
\hline \multirow[t]{2}{*}{$\geq 100$} & 38 & 24.4 & 7 & 8.0 & 45 & 18.4 & $\mathrm{Wx}=4.271, p<0.0001$ \\
\hline & Hospital A $(n=156)$ & & Hospital B $(n=89)$ & & Total $(n=245)$ & & \\
\hline ASA class & $n$ & $\%$ & $n$ & $\%$ & $n$ & $\%$ & \\
\hline $1-2$ & 25 & 16.0 & 8 & 8.9 & 33 & 13.5 & \\
\hline 3 & 96 & 61.5 & 50 & 56.2 & 146 & 59.6 & \\
\hline 4 & 35 & 22.4 & 31 & 34.9 & 66 & 26.9 & $\mathrm{Wx}=2.065, p<0.05$ \\
\hline Mortality(month) & & & & & & & $\mathrm{B} / \mathrm{A}, \mathrm{p}^{\mathrm{b}}$ \\
\hline 1 & 8 & 5.1 & 10 & 11.2 & 18 & 7.3 & 0.068 \\
\hline 2 & 11 & 7.1 & 14 & 15.7 & 25 & 10.2 & 0.280 \\
\hline 4 & 15 & 9.6 & 16 & 18.0 & 31 & 12.7 & 0.045 \\
\hline 12 & 26 & 16.7 & 21 & 23.6 & 47 & 19.2 & 0.124 \\
\hline 24 & 36 & 23.1 & 27 & 30.3 & 63 & 25.7 & 0.136 \\
\hline 36 & 50 & 32.1 & 37 & 41.6 & 87 & 35.5 & 0.426 \\
\hline
\end{tabular}

${ }^{\mathrm{a}}$ One sample missing; $W x$, Wilcoxon rank test; ${ }^{\mathrm{b}}$ Fisher's exact test

\section{Use of vitamin D and calcium supplements}

Pre-fracture use of vitamin D and calcium supplements was available to all patients. There were no differences between the hospitals regarding the pre-fracture use of vitamin D in all patients or between the patients in different serum25hydroxyvitamin D levels, except for one group. In hospital A, none of the 23 patients in the level of $<50 \mathrm{nmol} / \mathrm{L}$ used vitamin $\mathrm{D}$ supplements before the fracture, whereas in hospital $\mathrm{B}$, the percent of users in the corresponding level was $34.4 \%(11 / 32)(p<0.001)$. Moreover, no differences were between the hospitals in the pre-fracture use of calcium in all patients or between the patients in different serum 25-hydroxyvitamin D levels.

The use of vitamin D and calcium supplements at 3 months post-fracture was available in hospital B only. The use of both supplements increased significantly in all patients and in most levels (Supplementary Table 1). The most frequent pre- and post-fracture doses of vitamin D supplement were $400 \mathrm{IU} /$ day and $800 \mathrm{IU} /$ day, and the corresponding dose of calcium supplement was $500 \mathrm{mg} /$ day and $1000 \mathrm{mg} /$ day, respectively.

\section{Serum 25-hydroxyvitamin D level}

The mean serum 25-hydroxyvitamin D level was higher in hospital A than in hospital B: 79.2 (SD 31.7) nmol/L vs. 62.4 (SD 27.5) nmol/L, $p<0.001$, respectively. The mean level in men was 67 (SD 31) nmol/L and in women 75.8
(SD 31.1) nmol/L $(p<0.05)$ [20]. The range of levels was $5-135 \mathrm{nmol} / \mathrm{L}$ in men and $5-170 \mathrm{nmol} / \mathrm{L}$ in women.

There were significant differences in the distribution of serum 25-hydroxyvitamin D levels between the hospitals. More patients in hospital B than in hospital A had a level below $50 \mathrm{nmol} / \mathrm{L}$ (Table 1). The highest concentration in women was in hospital A and in men in hospital B.

The mean age of patients according to serum 25 -hydroxyvitamin D levels of $<50 \mathrm{nmol} / \mathrm{L}, 50-99 \mathrm{nmol} / \mathrm{L}$, and $\geq 100 \mathrm{nmol} / \mathrm{L}$ was 76.7 (SD 11.7), 81.9 (SD 9.7), and 79 (SD 9.6) years, respectively ( $F$-test $5.93, d f=2 ; 238$, $p<0.01)$. No difference in the distribution of the ASA classes 1-2, 3, and 4 was found between the corresponding three serum 25-hydroxyvitamin D levels (Kruskal-Wallis $=5.18, d f=2$, n.s.).

\section{Mortality and survival}

At the end of the follow-up period, $57.1 \%$ of the patients (140/245) were alive and 42.9\% (105/245) were dead. Of the total population, 59.1\% (101/171) of women and $47.3 \%$ (39/74) of men were alive. The mean age of female survivors was 77.8 years (SD 9.3 years) and that of male survivors 74.3 (SD 12.4). Of those who did not survive, the mean age was in women 86.4 (SD 7.3) years and in men 82.1 (SD 9.8) years $(F$-test $6.37, d f=1 ; 240, p<0.01)$. Overall, survivors were significantly younger than those who did not survive: mean ages 76.8 (SD 10.4) years vs. 84.9 (SD 8.4) years, respectively ( $F$-test $44.00, d f=1 ; 240, p<0.001)$. 
Table 2 Cumulative mortality of 244 patients at 12,24 , and 36 months according to serum 25-hydroxyvitamin D level $(\mathrm{nmol} / \mathrm{L})$

\begin{tabular}{|c|c|c|c|c|c|c|c|c|c|c|c|}
\hline \multirow[b]{3}{*}{ Months } & \multirow{2}{*}{\multicolumn{2}{|c|}{$\begin{array}{l}\text { Group A } \\
<50 \mathrm{nmol} / \mathrm{L} \\
(n=55)\end{array}$}} & \multirow{2}{*}{\multicolumn{2}{|c|}{$\begin{array}{l}\text { Group B } \\
50-74 \mathrm{nmol} / \mathrm{L} \\
(n=75)\end{array}$}} & \multirow{2}{*}{\multicolumn{2}{|c|}{$\begin{array}{l}\text { Group C } \\
75-99 \mathrm{nmol} / \mathrm{L} \\
(n=69)\end{array}$}} & \multirow{2}{*}{\multicolumn{2}{|c|}{$\begin{array}{l}\text { Group D } \\
\geq 100 \mathrm{nmol} / \mathrm{L} \\
(n=45)\end{array}$}} & \multirow{2}{*}{\multicolumn{2}{|c|}{$\begin{array}{l}\text { Total } \\
\left(n=244^{\mathrm{a}}\right)\end{array}$}} & \multirow{3}{*}{$\begin{array}{l}\mathrm{B} /(\mathrm{A}+\mathrm{C}+\mathrm{D}) \\
\mathrm{p}^{\mathrm{b}}\end{array}$} \\
\hline & & & & & & & & & & & \\
\hline & $n$ & $\%$ & $n$ & $\%$ & $n$ & $\%$ & $n$ & $\%$ & $n$ & $\%$ & \\
\hline 12 & 15 & 27.3 & 8 & 10.7 & 12 & 17.4 & 12 & 26.7 & 47 & 19.3 & 0.0155 \\
\hline 24 & 21 & 38.2 & 12 & 16.0 & 16 & 23.2 & 14 & 31.1 & 63 & 25.8 & 0.0130 \\
\hline 36 & 24 & 43.6 & 20 & 26.7 & 24 & 34.8 & 18 & 40.0 & 86 & 35.2 & 0.0412 \\
\hline
\end{tabular}

Kruskal-Wallis $1.809, d f=3$, n.s.; ${ }^{\text {a }}$ one sample missing; ${ }^{\text {}}$ Fisher's exact test
Cumulative mortality rates according to hospital at 1,2 , 4, 12, 24, and 36 months are shown in Table 1. One-year mortality was $19.2 \%$ : $16.7 \%$ in hospital A and $23.7 \%$ in hospital B (n.s.). At 4 months, the mortality was significantly higher in hospital B.

The distribution of cumulative mortality according to serum 25-hydroxyvitamin D levels is shown in Table 2. Mortality in the level of $50-74 \mathrm{nmol} / \mathrm{L}$ was significantly lower than that of all other levels together at 12, 24, and 36 months (Table 2).

In the univariate and multivariate analyses, the following distribution of serum 25-hydroxyvitamin $\mathrm{D}$ levels was used: $<25,25-49,50-74,75-99$, and $\geq 100 \mathrm{nmol} / \mathrm{L}$. The univariate analysis included the following variables: sex, age, serum 25-hydroxyvitamin D level, ASA class, place of residence, and type of fracture (Table 3 ).
Table 3 Univariate analysis of 6 variables in relation to survival data $(n=245)^{\mathrm{a}}$

\begin{tabular}{|c|c|c|c|c|c|c|}
\hline Variable & Negative & Positive & Total & OR & $95 \% \mathrm{CI}$ & Statistic \\
\hline \multicolumn{7}{|l|}{ Sex } \\
\hline Male & 39 & 35 & 74 & 1.30 & $0.75-2.24$ & \\
\hline Female & 101 & 70 & 171 & 0.77 & $0.45-1.34$ & $\chi^{2}=0.85, d f=1, \mathrm{n} . \mathrm{s}$ \\
\hline \multicolumn{7}{|l|}{ Age } \\
\hline$<65$ & 16 & 3 & 19 & 0.228 & $0.07-0.73$ & \\
\hline $65-74$ & 33 & 10 & 43 & 0.341 & $0.16-0.71$ & \\
\hline $75-84$ & 58 & 27 & 85 & 0.489 & $0.28-0.85$ & \\
\hline$\geq 85$ & 33 & 65 & 98 & 5.269 & $3.08-9.03$ & $\mathrm{Wx}=5.71, p<0.001$ \\
\hline \multicolumn{7}{|l|}{$\mathrm{S}-25 \mathrm{OHD}(\mathrm{nmol} / \mathrm{L})^{\mathrm{b}}$} \\
\hline$<25$ & 8 & 7 & 15 & 1.19 & $0.42-3.38$ & \\
\hline $25-49$ & 18 & 22 & 40 & 1.82 & $0.92-3.59$ & \\
\hline $50-74$ & 49 & 26 & 75 & 0.62 & $0.35-1.09$ & \\
\hline $75-99$ & 49 & 29 & 69 & 0.98 & $0.59-1.63$ & \\
\hline$\geq 100$ & 25 & 20 & 45 & 1.10 & $0.57-2.09$ & $\mathrm{Wx}=0.477, \mathrm{n} . \mathrm{s}$ \\
\hline \multicolumn{7}{|l|}{ ASA class } \\
\hline $1-2$ & 30 & 3 & 33 & 0.12 & $0.04-0.31$ & \\
\hline 3 & 86 & 60 & 146 & 0.84 & $0.50-1.40$ & \\
\hline 4 & 24 & 42 & 66 & 3.22 & $1.91-5.73$ & $\mathrm{Wx}=4.47, p<0.001$ \\
\hline \multicolumn{7}{|l|}{ Place of residence } \\
\hline Actual/privat home & 117 & 60 & 177 & 0.26 & $0.15-0.47$ & \\
\hline Residential home & 9 & 16 & 25 & 2.62 & $1.13-6.05$ & \\
\hline Residential home $24 \mathrm{~h}$ & 12 & 25 & 37 & 3.33 & $1.63-6.93$ & \\
\hline Hospital & 2 & 4 & 6 & 2.73 & $0.52-14.29$ & $\chi^{2}=18.01, d f=3, p<0.001$ \\
\hline \multicolumn{7}{|l|}{ Type of fracture } \\
\hline Femoral neck & 78 & 65 & 143 & 1.29 & $0.77-2.17$ & \\
\hline Trochanteric & 51 & 33 & 84 & 0.80 & $0.47-1.37$ & \\
\hline Subtrochanteric & 11 & 7 & 18 & 0.84 & $0.31-2.23$ & $\chi^{2}=0.95, d f=2, \mathrm{n} . \mathrm{s}$ \\
\hline
\end{tabular}

$\chi^{2}$, chi-squared test; $A S A$, American Society of Anesthesiologists; $d f$, degrees of freedom; $O R$, odds ratio; n.s., not significant; $S$-25OHD, serum 25-hydroxyvitamin D; $W x$, Wilcoxon rank test

${ }^{\mathrm{a}}$ All the classes of the variables are compared with each other within the variable; ${ }^{\mathrm{b}} n=244$ 
Table 4 The most important factors (in italics) predicting survival selected out of six variables in 245 patients

\begin{tabular}{llllll}
\hline RR limit & $\begin{array}{l}\text { False nega- } \\
\text { tive count }\end{array}$ & Sensitivity & Specificity & $\kappa$ & Added variable \\
\hline 0.49 & 40 & 61.9 & 76.4 & 0.387 & Age (<85 years) \\
0.76 & 25 & 76.2 & 68.6 & 0.438 & $\begin{array}{l}\text { Place of residence (actual/private home) } \\
0.15\end{array}$ \\
& 15 & 85.7 & 61.4 & 0.451 & $\begin{array}{l}\text { Serum 25-hydroxyvitamin D level } \\
(50-74 \text { nmol/L and } 75-99 \text { nmol/L) }\end{array}$ \\
0.28 & 20 & 81.0 & 67.9 & 0.474 & ASA class $(1-3)$ \\
0.23 & 15 & 85.7 & 66.4 & 0.502 & Sex (female) \\
& 18 & 82.9 & 57.1 & 0.484 & Type of fracture \\
\hline
\end{tabular}

$A S A$, American Society of Anesthesiologists; $R R$, risk ratio
In the multivariate analysis, the protective factors for survival, in order of importance, were age under 85 years; living in actual/private home; serum 25-hydroxyvitamin D level of $50-74 \mathrm{nmol} / \mathrm{L}$, followed by $75-99 \mathrm{nmol} / \mathrm{L}$; ASA classes 1-2 and 3; and female sex (Table 4). The model correctly predicted $75 \%$ of the cases. The sensitivity and specificity of the rule were $86 \%$ and $66 \%$, respectively (Supplementary Table 1). The kappa value was 0.50 (95\% CI: $0.40-0.61)$, i.e., moderate. The graphic description of the model (ROC) is shown in Supplementary Fig. 1.

\section{Relative survival}

The survival rates during the follow-up period varied according to serum 25-hydroxyvitamin $\mathrm{D}$ level especially among men $(n=74)$ (Fig. 1). Men with a level of $50-74 \mathrm{nmol} / \mathrm{L} \mathrm{had}$ the highest survival. Survival was second highest in men with a level of 75-99 nmol/L from 11 months onwards. Men with a serum 25-hydroxyvitamin D level of $\geq 100 \mathrm{nmol} / \mathrm{L}$ had the lowest survival, and the second lowest survival was among those with a level below $50 \mathrm{nmol} / \mathrm{L}$ (Fig. 1).
In women $(n=170)$, no respective variation was seen in the corresponding survival curves (Fig. 2). The survival was highest among women with serum 25-hydroxyvitamin D of $50-74 \mathrm{nmol} / \mathrm{L}$ and second highest among those with a level of $75-99 \mathrm{nmol} / \mathrm{L}$. The lowest survival was among women with a level below $50 \mathrm{nmol} / \mathrm{L}$ after 13 months (Fig. 2).

The survival according to serum 25-hydroxyvitamin D level in hospital B is presented in Supplementary Fig. 2. The highest survival was among patients with a serum 25-hydroxyvitamin D level of 50-74 $\mathrm{nmol} / \mathrm{L}$ and the lowest among patients with a level of $\geq 100 \mathrm{nmol} / \mathrm{L}(n=7)$ (Supplementary Fig. 2).

\section{Discussion}

In the present study, we analyzed the mortality and survival of 245 low-energy hip fracture patients. The 1-year mortality in the total data (19.2\%) was lower than the global rate (22.8\%) [8]. However, it was higher in hospital B than in hospital A ( $23.5 \%$ vs. $16.7 \%$, respectively), and at 4 months, the difference was significant. Since 2006,
Fig. 1 Relative survival of men $(n=74)$ according to serum 25-hydroxyvitamin D level during the follow-up

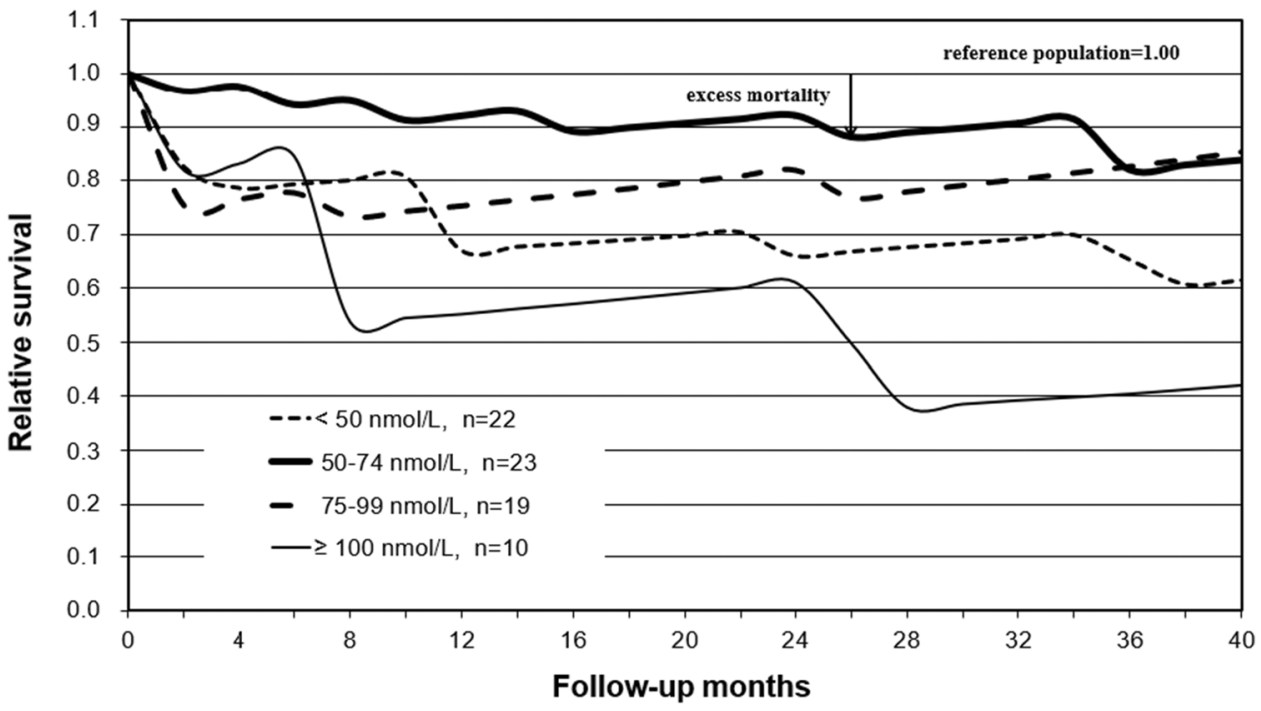


Fig. 2 Relative survival of women $(n=170)$ according to serum 25-hydroxyvitamin D level during the follow-up

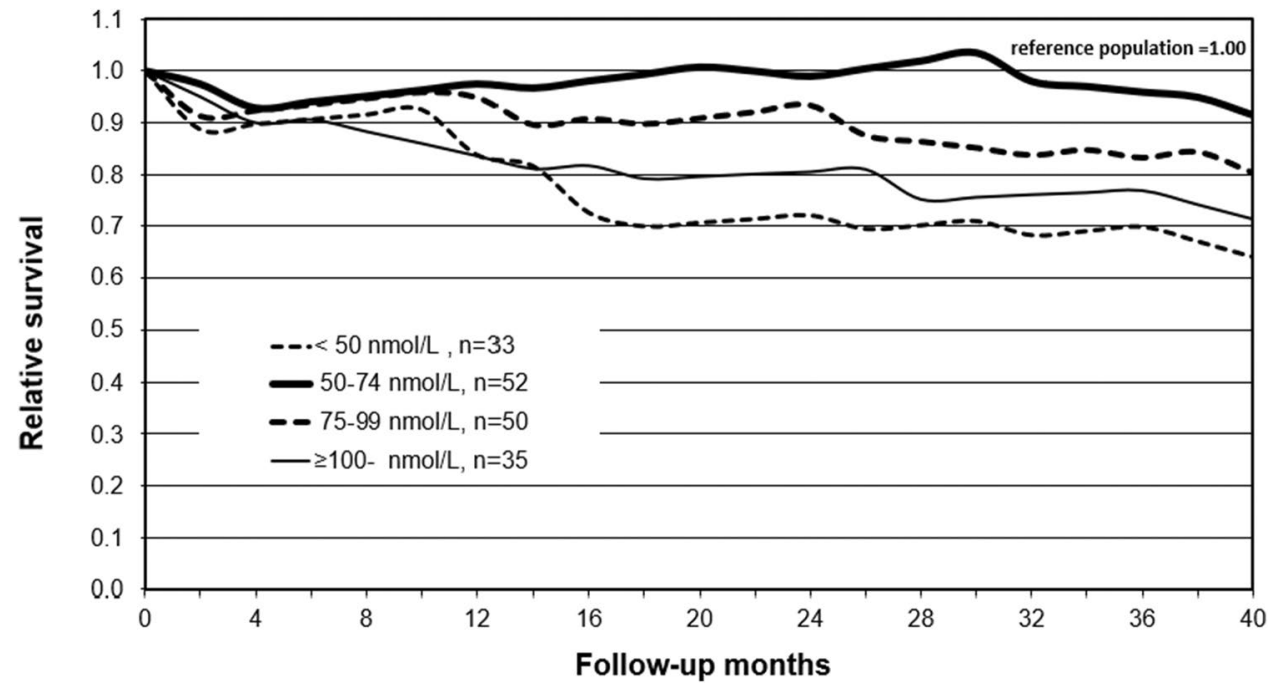

postoperative rehabilitation in hospital A has been centralized in a single rehabilitation ward with a multidisciplinary rehabilitation team including a geriatrician, whereas in hospital B, the postoperative rehabilitation was distributed to general wards in local health center. A systematic review and meta-analysis indicated that in comparison to usual care, orthopedic geriatric rehabilitation programs improved patients' functional status and decreased mortality [27].

The combination of variables that best explained the survival at the end of follow-up was age under 85 years, living in an actual/private home, serum 25-hydroxyvitamin D level of 50-74 and 75-99 nmol/L, ASA classes 1-2 and 3 , and female sex. Interestingly, the mean age was highest among patients with serum 25-hydroxyvitamin D level of 50-99 nmol/L, whose survival appeared the highest. The survival in relation to the reference population was highest among women and men with serum 25-hydroxyvitamin D level of 50-74 nmol/L during the entire follow-up. The highest relative survival in men with this level was seen quite soon after the index fracture and in women from 12 months onwards.

In our previous study in 2003-2004 among a corresponding cohort of hip fracture patients $(n=221)$ with 11-year follow-up, the protective factors for survival were age $<80$ years; ASA classes 1-2; pre-fracture serum 25-hydroxyvitamin level above $50 \mathrm{nmol} / \mathrm{L}$; post-fracture use of prescribed calcium plus vitamin D; post-fracture concomitant use of prescribed calcium plus vitamin D and antiosteoporotic drugs; and male sex [10]. For the present study, the use of vitamin D and calcium could not be obtained from the national prescription register because currently, these supplements are available over the counter in Finland. The register contains data on all prescribed medications purchased in any pharmacy in Finland [28].
Furthermore, serum 25-hydroxyvitamin D in the previous study was categorized into three subgroups: <25, 25-49, and $\geq 50 \mathrm{nmol} / \mathrm{L}$. Only six patients (3\%) achieved the level of $\geq 75 \mathrm{nmol} / \mathrm{L}$. The highest survival at the end of followup was among patients with a level above $50 \mathrm{nmol} / \mathrm{L}$, followed by those of $25-49 \mathrm{nmol} / \mathrm{L}$. Survival was clearly lowest with a level below $25 \mathrm{nmol} / \mathrm{L}$. After 7 years postoperatively, the excess mortality of patients with a level of $\geq 50 \mathrm{nmol} / \mathrm{L}$ ended, and the mortality rate remained steady during the following 4 years [10].

In the present study, in turn, the excess mortality of the patients on different serum 25-hydroxyvitamin D levels came to an end earlier: at 1 year among men with both a level of 74-99 $\mathrm{nmol} / \mathrm{L}$ and $<50 \mathrm{nmol} / \mathrm{L}$, whereas the survival of men with a level of 50-74 nmol/L was highest at up to 36 months. In women, the highest survival was in those with a level of 50-74 nmol/L, persisting for the entire follow-up and rising twice even higher than that of the reference population.

The vitamin D status of the Finnish adult population has substantially improved between the years 2000 and 2011 with the mean serum 25-hydroxyvitamin D level increasing from 48 to $65 \mathrm{nmol} / \mathrm{L}$ [29]. Similarly, in 2003-2004, the mean levels among female and male hip fracture patients were $38.1 \mathrm{nmol} / \mathrm{L}$ (SD 15.8) and $37.0 \mathrm{nmol} / \mathrm{L}$ (SD 16.4), respectively [19], whereas, in the present data, the corresponding mean values were remarkably improved: 75.8 (SD 31.1) nmol/L among women and 67.0 (SD 31.0) nmol/L among men [20]. The increase is mainly explained by the systematic vitamin D fortification of food, which started in 2003 in Finland, especially of fat spreads and fluid milk products that are widely used by the Finnish population, and by augmented use of vitamin D supplements [29]. The consumption of fluid milk products per person among Finns was highest in the world in 2015 [30]. 
In Denmark, serum 25-hydroxyvitamin D level of $50-60 \mathrm{nmol} / \mathrm{L}$ was associated with the lowest mortality risk among the general population with nearly 250,000 subjects analyzed from the Copenhagen $\left(55^{\circ} \mathrm{N}\right)$ general practice sector. Compared to $50 \mathrm{nmol} / \mathrm{L}$, the hazard ratios of all-cause mortality at very low $(10 \mathrm{nmol} / \mathrm{L})$ and high $(140 \mathrm{nmol} / \mathrm{L})$ serum levels of 25 -hydroxyvitamin D were 2.13 (2.02-2.24) and 1.42 (1.31-1.53), respectively. During the 3-year follow-up, a reverse J-shaped association between serum 25-hydroxyvitamin D level and mortality was observed [31].

A large European meta-analysis [11] of eight prospective studies ( $n=26,916$, median age 61.6 years), with a median follow-up time of 10.5 years, showed that participants with a level of 75-99 nmol/L had the lowest all-cause mortality in comparison to patients with a level below $30 \mathrm{nmol} / \mathrm{L}$, $30-40 \mathrm{nmol} / \mathrm{L}$, and $40-50 \mathrm{nmol} / \mathrm{L}$. Thresholds of serum 25-hydroxyvitamin D levels were defined according to the Institute of Medicine [14] and Endocrine Society [15] as follows: severely vitamin $\mathrm{D}$ deficient $(<30 \mathrm{nmol} / \mathrm{L})$; inadequate (30-49 nmol/L); vitamin D sufficient (50-74 nmol/L); two ranges of vitamin $D$ level that are sufficient but not consistently associated with increased benefit $(75-99 \mathrm{nmol} / \mathrm{L}$ and $100-124 \mathrm{nmol} / \mathrm{L}$ ); and high vitamin D concentration $(>125 \mathrm{nmol} / \mathrm{L}$ ) with a possible reason for concern. Low serum 25 -hydroxyvitamin D levels $(<50 \mathrm{nmol} / \mathrm{L})$ were significantly associated with all-cause and cardiovascular mortality. However, the risk of all-cause mortality in the level of 50-74 nmol/L was marginal: $\mathrm{HR}=1.05$ (96\% CI: 0.93-1.16); but the death risk from cardiovascular causes was obvious: $\mathrm{HR}=1.35(1.12-1.63)$. There was no significantly increased mortality risk at high serum 25 -hydroxyvitamin D levels from 100 to $125 \mathrm{nmol} / \mathrm{L}$ [11].

There are a limited number of reports in the literature on the association between vitamin $\mathrm{D}$ concentration and postfracture mortality among hip fracture patients. In Denmark, a study among 562 hip fracture patients and 21,778 controls showed no association between serum 25-hydroxyvitamin D and mortality [32]. Similarly, in a Korean study [33] on 489 hip fracture patients, no relationship between serum 25-hydroxyvitamin D levels and 1-year mortality after hip fracture was seen in multivariate analysis, although $89 \%$ of patients were vitamin D deficient $(<50 \mathrm{nmol} / \mathrm{L})$ or insufficient $(<75 \mathrm{nmol} / \mathrm{L})$ according to the definition of Holick [34]. However, the univariate analysis showed that mortality was associated with vitamin D deficiency $(p=0.012)$ [33].

In a German prospective study [35] among 209 elderly patients (mean age 81 years) with femoral neck fractures, vitamin D concentration was determined using Holick's [34] definition. Vitamin D deficiency $(<75 \mathrm{nmol} / \mathrm{L})$ was prevalent in $87 \%$ of patients. One year mortality was $29 \%$ and $13 \%$, respectively, in patients with severe $(<25 \mathrm{nmol} / \mathrm{L})$ and moderate (25-50 nmol/L) vitamin D deficiency, compared to $9 \%$ in patients with serum 25 -hydroxyvitamin D above
$50 \mathrm{nmol} / \mathrm{L}(p=0.027)$. Multiple logistic regression analysis identified CRP but not serum 25-hydroxyvitamin D as an independent predictor of 1-year mortality. However, serum 25 -hydroxyvitamin $\mathrm{D}$ above $75 \mathrm{nmol} / \mathrm{L}$ was independently associated with postoperative medical complications [35].

In a very recent retrospective study from Singapore, $90 \%$ of 801 hip fracture patients (mean age 77.7 years) had a baseline serum 25-hydroxyvitamin D level of less than75 $\mathrm{nmol} / \mathrm{L}$, and their 2-year mortality was $11.0 \%$ [36].

Post-fracture use of vitamin D and calcium supplements was not studied in the earlier referred studies among hip fracture patients, except for our previous study [10]. In addition, we studied the post-fracture use of these supplements among hip fracture patients in a nationwide Finnish data set [37]. In both of the previous studies [10,37], post-fracture use of vitamin D along with calcium improved the survival of hip fracture patients. In the present study, the information on the post-fracture use of vitamin $D$ and calcium supplements was available only in hospital B, where the use of these supplements significantly increased in most serum 25-hydroxyvitamin levels after a fracture. The increased use may have benefitted mostly the patients with a serum 25-hydroxyvitamin level of 50-74 nmol/L. A similar improvement in survival was not seen among patients with other levels. Patients with levels of $\geq 100 \mathrm{nmol} / \mathrm{L}$ had the lowest survival. However, the number of patients was very small.

According to Finnish hip fracture guidelines [38], a minimum of 400-800 IU per day vitamin D supplement postfracture and a minimum of 1000 to $1500 \mathrm{mg} /$ day calcium are recommended to all patients who have sustained a hip fracture. We assume that the guidelines have also been followed for the patients from hospital A.

The present result on the lower threshold of serum 25-hydroxyvitamin D $(50 \mathrm{nmol} / \mathrm{L})$ is in line with the recommendation of the Finnish Food Authority [39] and with the expert consensus recommendation published by Munns et al. [13]. However, the upper threshold for desirable level $(99 \mathrm{nmol} / \mathrm{L})$ is lower than that stated in the Finnish hip fracture guidelines $(75-120 \mathrm{nmol} / \mathrm{L})$ [38].

Thus far, the upper safe threshold for serum 25-hydroxyvitamin D level has not been defined. The International Osteoporosis Foundation has defined the upper threshold of adequate level as $110 \mathrm{nmol} / \mathrm{L}$ [40]. In the present data, levels $\geq 100 \mathrm{nmol} / \mathrm{L}$ were no longer protective. An expert opinion has been presented that the minimum blood level of 25-hydroxyvitamin $\mathrm{D}$ that would be optimal for fracture prevention is $50-80 \mathrm{nmol} / \mathrm{L}$, more specifically, $70-80 \mathrm{nmol} / \mathrm{L}$ [41]. Those levels are in line with our present results as optimal levels among hip fracture patients.

The present result regarding 1-year mortality among patients with serum 25-hydroxyvitamin D level of $50-74 \mathrm{nmol} / \mathrm{L}$ is in line with that of German patients [35] (11\% vs. 9\%, respectively). However, the corresponding mortality among patients with a level $<50 \mathrm{nmol} / \mathrm{L}$ was 
lower in the present study ( $27 \%$ vs. $42 \%$, respectively). Two-year mortality in the level less than $75 \mathrm{nmol} / \mathrm{L}$ was also slightly higher (13.5\%) in the present study than was found in Singapore (11\%) [36].

The classification of serum 25-hydroxyvitamin D levels and the survival results of the present study are closest to those reported by Gaksch et al. [11] among the general population with remarkably larger data than in the present study. In their study, a level of 50-74 nmol/L was defined as sufficient. In their meta-analysis, the lowest all-cause mortality was among those with a level of 75-99 nmol/L, although the mortality risk in the level of $50-74 \mathrm{nmol} / \mathrm{L}$ was also close to that rate but not significantly. Contrary to our results, high serum 25-hydroxyvitamin D levels from 100 to $125 \mathrm{nmol} / \mathrm{L}$ did not increase mortality risk [11]. Moreover, in the Danish general population [30], an optimal level of $60-80 \mathrm{nmol} / \mathrm{L}$, indicating the highest 3-year survival, is parallel to our findings.

In the present study, the desirable serum 25-hydroxyvitamin D level of 50-74 $\mathrm{nmol} / \mathrm{L}$ for highest survival and lowest mortality in the present hip fracture cohort during the follow-up time was confirmed in all performed analyses. Interestingly, in our very recent study [42] among 525 patients with low-energy fractures, serum 25-hydroxyvitamin D levels of 50-74 nmol/L and 75-119 nmol/L, in order of importance, were associated with the highest survival with a minimum follow-up of 3.5 years.

The follow-up time of the present study was up to December 30, 2019, and the first SARS-CoV-2 virus infection was reported on January 19, 2020, in Lapland, Northern Finland. The first death due to the SARS-CoV-2 virus in Finland was on March 20, 2020. Therefore, the pandemic did not have any effect on the patients of the present study.

The strength of the present study is the prospective design. Moreover, all serum 25-hydroxyvitamin D concentrations were analyzed in the same laboratory using the same method standardized to the NIST standard. The survival of all patients was followed for 3.2 years. Only native-born Finns were included in our data, and no other ethnic groups were represented. The foreign-born population in Finland is small (6\%), and less than $3 \%$ of foreign-born persons lived in the study area in 2015 (Statistics Finland). The population $\geq 50$ years of age in the present study represents $6 \%$ of the similar Finnish population (Statistics Finland), and the number of hip fractures in the present data composes $4 \%$ of all acute hip fractures in Finland in the study year [43].

The present study has several limitations. Information on the length of hospital stay after hip fracture, complications, comorbidities, or causes of death was not available in the present cohort of patients. Unlike in our previous studies [10,37], the use of the supplements could no longer be obtained from the national prescription register, which is a regrettable limitation.
Pre-fracture use of vitamin D and calcium supplements was manually collected in admission by the staff in both hospitals, and post-fracture use of these supplements was obtained from patients' medical drug records. Unfortunately, post-fracture use of vitamin $\mathrm{D}$ and calcium supplements was only available in hospital B. In hospital A, access to the electronic patient records at 3 months post-fracture was not possible due to different electronic systems in the further rehabilitation units where the patients were situated at that time. Thus, we performed a sub-analysis on relative survival according to serum 25-hydroxyvitamin D level only among hospital B patients.

We cannot state that the hospital B patients continuously used these supplements until the end of the follow-up as we have this information only at 3 months postoperatively. Nor was it possible to examine the serum 25 -hydroxyvitamin D levels during the follow-up because this would require excessive financial resources.

Because of the limitations and the relatively small data, the results cannot be generalized, and they should be studied in larger data. The results may be directional, and they should be confirmed in further research.

\section{Conclusion}

In the present hip fracture cohort, pre-fracture serum 25-hydroxyvitamin D level for the highest 3-year survival and lowest mortality appeared to be $50-74 \mathrm{nmol} / \mathrm{L}$. This result differs from results in similar studies and is lower than the currently recommended level of serum 25-hydroxyvitamin D among hip fracture patients. To confirm the result, the study should be examined in future research with larger data. The present study represents a time period before the SARS-CoV-2 pandemic in Finland.

Supplementary Information The online version contains supplementary material available at https://doi.org/10.1007/s00198-021-06094-z.

Funding This work was supported by the Centenary Foundation of Kymi Corporation, Finland, and the Research Foundations of Helsinki and Tampere University Hospitals, Finland.

\section{Declarations}

Conflicts of interest None.

\section{References}

1. Lüthje P, Helkamaa T, Kaukonen J-P, Nurmi-Lüthje I, Kataja M (2012) A long-term follow-up of 221 hip fracture patients in southeastern Finland: analysis of survival and prior or subsequent fractures. Arch Gerontol Geriatr 54:e294-e299. https://doi.org/10. 1016/j.archger.2011.12.002 
2. Abrahamsen B, van Staa T, Ariely R, Olson M, Cooper C (2009) Excess mortality following hip fracture: a systematic epidemiological review. Osteoporos Int 20:1633-1650. https://doi.org/10. 1007/s00198-009-0920-3

3. Haentjens P, Magaziner J, Colon-Emeric CS, Vanderschueren D, Milisen K, Velkeniers B, Boonen S (2010) Meta-analysis: excess mortality after hip fracture among older women and men. Ann Intern Med 152:380-90. https://doi.org/10.7326/0003-4819-1526-201003160-00008

4. Diamantopoulos AP, Hoff M, Skoie IM, Hochberg M, Haugeberg G (2013) Short- and long-term mortality in males and females with fragility hip fracture in Norway. A population-based study Clin Interv Aging 8:817-823. https://doi.org/10.2147/CIA. S45468

5. Åhman R, Siverhall PF, Snygg J, Fredrikson M, Enlund G, Björnström K, Chew MS (2018) Determinants of mortality after hip fracture surgery in Sweden: a registry-based retrospective cohort study. Sci Rep 8:15695. https://doi.org/10.1038/ s41598-018-33940-8

6. Reito A, Kuoppala M, Pajulampi H, Hokkinen L, Kyrölä K, Paloneva J (2019) Mortality and comorbidity after non-operatively managed, low-energy pelvic fracture in patients over age 70: a comparison with an age-matched femoral neck fracture cohort and general population. BMC Geriatr 19:315. https://doi.org/10. 1186/s12877-019-1320-y

7. Egol KA, Koval KJ, Zuckerman JD (1997) Functional recovery following hip fracture in the elderly. J Orthop Trauma 11:594 599. https://doi.org/10.1097/00005131-199711000-00009

8. Downey C, Kelly M, Quinlan JF (2019) Changing trends in the mortality rate at 1-year post hip fracture - a systematic review. World J Orthop 10:166-175. https://doi.org/10.5312/wjo.v10.i3. 166

9. Lee YK, Lee YJ, Ha YC, Koo KH (2014) Five-year relative survival of patients with osteoporotic hip fracture. J Clin Endocrinol Metab 99:97-100. https://doi.org/10.1210/jc.2013-2352

10. Nurmi-Lüthje I, Lüthje P, Kaukonen JP, Kataja M (2015) Positive effects of a sufficient pre-fracture serum vitamin D level on the long-term survival of hip fracture patients in finland: a minimum 11-year follow-up. Drugs Aging 32:477-486. https://doi.org/10. 1007/s40266-015-0267-8

11. Gaksch M, Jorde R, Grimnes G, Joakimsen R, Schirmer H, Wilsgaard T, Mathiesen EB, Njølstad I, Løchen ML, März W, Kleber ME, Tomaschitz A, Grübler M, Eiriksdottir G, Gudmundsson EF, Harris TB, Cotch MF, Aspelund T, Gudnason V, Rutters F, Beulens JW, van 't Riet E, Nijpels G, Dekker JM, GroveLaugesen D, Rejnmark L, Busch MA, Mensink GB, Scheidt-Nave C, Thamm M, Swart KM, Brouwer IA, Lips P, van Schoor NM, Sempos CT, Durazo-Arvizu RA, Škrabáková Z, Dowling KG, Cashman KD, Kiely M, Pilz S (2017) Vitamin D and mortality: individual participant data meta-analysis of standardized 25hydroxyvitamin D in 26916 individuals from a European consortium. PLoS One 12:e0170791. https://doi.org/10.1371/journ al.pone.0170791

12. Hansen KE, Johnson MG (2016) An update on vitamin D for clinicians. Curr Opin Endocrinol Diabetes Obes 23:440-444. https:// doi.org/10.1097/MED.0000000000000288

13. Munns GF, Shaw N, Kiely M, Specker BL, Thacher TD, OzonoK MT, Tiosano D, Zulf Mughal M, Mäkitie O, Ramos-Abad L, Ward L, DiMeglio LA, Atapattu N, Cassinelli H, Braegger C, Pettifor JM, Seth A, Idris HW, Bhatia V, Fu J, Goldberg G, Sävendahl L, Khadgawat R, Pludowski P, Maddock J, Hyppönen E, Oduwole A, Frew E, Aguiar M, Tulchinsky T, Butler G, Högler W (2016) Global consensus recommendations on prevention and management of nutritional rickets. J Clin Endocrinol Metab 101:394-415. https://doi.org/10.1210/jc.2015-2175
14. Ross AC, Manson JE, Abrams SA, Aloia JF, Brannon PM, Clinton SK, Durazo-Arvizu RA, Gallagher JC, Gallo RL, Jones G, Kovacs CS, Mayne ST, Rosen CJ, Shapses SA (2011) The 2011 report on dietary reference intakes for calcium and vitamin $\mathrm{D}$ from the Institute of Medicine: what clinicians need to know. J Clin Endocrinol Metab 96:53-58. https://doi.org/10.1210/jc.2010-2704

15. Holick MF, Binkley NC, Bischoff-Ferrari HA, Gordon CM, Hanley DA, Heaney RP, Murad MH, Weavwe CM (2011) Evaluation, treatment, and prevention of vitamin D deficiency: an Endocrine Society Clinical Practice Guideline. J Clin Endocrinol Metab 96:1911-1930. https://doi.org/10.1210/jc.2011-0385

16. Nordic Council of Ministers (2014 ) Nordic Nutrition Recommendations 2012. Integrating nutrition and physical activity. http:// norden.diva-portal.org/smash/get/diva2:704251/FULLTEXT01. pdf (accessed April 4, 2021)

17. Ingstad F, Solberg LB, Nordsletten L, Thorsby PM, Hestnes I, Frihagen F (2020) Vitamin D status and complications, readmissions, and mortality after hip fracture. Osteoporos Int 32:873-881. https://doi.org/10.1007/s00198-020-05739-9

18. Bischoff-Ferrari HA, Dawson-Hughes B, Orav EJ, Staehelin HB, Meyer OW, Theiler R, Dick W, Willett WC, Eg A (2016) Monthly high-dose vitamin $\mathrm{D}$ treatment for the prevention of functional decline: a randomized clinical trial. JAMA Intern Med 176:175183. https://doi.org/10.1001/jamainternmed.2015.7148

19. Nurmi I, Kaukonen JP, Lüthje P, Naboulsi H, Tanninen S, Kataja M, Kallio ML, Leppilampi M (2005) Half of the patients with an acute hip fracture suffer from hypovitaminosis D: a prospective study in southeastern Finland. Osteoporos Int 16:2018-2024. https://doi.org/10.1007/s00198-005-1987-0

20. Nurmi-Lüthje I, Tiihonen R, Paattiniemi E-L, Naboulsi H, Pigg S, Sarkkinen H, Kaukonen J-P, Toivanen A, Salmio K, Kataja M, Lüthje P (2018) Remarkable improvement in serum 25-hydroxyvitamin levels among hip fracture patients in 12 years: a prospective study in southeastern Finland. Erratum in: Osteoporos Int Mar 5;(open access) Osteoporos Int 29: 837-845. https://doi.org/10. 1007/s00198-017-4344-1

21. Vogeser M, Kyriarsoulis A, Huber E, Kobold U (2004) Candidate reference method for the quantification of circulating 25-hydroxyvitamin $\mathrm{D} 3$ by liquid chromatography-tandem mass spectrometry. Clin Chem 50:1415-1417. https://doi.org/10.1373/clinchem.2004. 031831

22. Phinney KW (2008) Development of a standard reference material for vitamin D in serum. Am J Clin Nutr 88(suppl):511-512. https://doi.org/10.1093/ajcn/88.2.511S

23. Sankar A, Johnson SR, Beattie WS, Wijeysundera DN (2014) Reliability of the American Society of Anesthesiologists physical status scale in clinical practice. Br J Anaesth 113:424-432. https:// doi.org/10.1093/bja/aeu100

24. Hanley JA, McNeil BJ (1982) The meaning and use of the area under a receiving operating characteristics (ROC) curve. Radiology 143:29-36. https://doi.org/10.1148/radiology.143.1.7063747

25. Altman DG (1991) Practical statistics for medical research. Chapman \& Hall, London

26. Hakulinen T (1977) On long-term relative survival rates. J Chronic Dis 30:431-443. https://doi.org/10.1016/0021-9681(77) 90036-4

27. Bachmann S, Finger C, Huss A, Egger M, Stuck AE, Clough-Gorr KM (2010) Inpatient rehabilitation specifically designed for geriatric patients: systematic review and meta-analysis of randomised controlled trials. BMJ 340:c1718. https://doi.org/10.1136/bmj. c1718

28 Rauma P, Honkanen R, Williams L, Tuppurainen M, Kröger H, Koivumaa-Honkanen H (2016) Effects of antidepressants on postmenopausal bone loss - a 5-year longitudinal study from the OSTPRE cohort. Bone 89:25-31. https://doi.org/10.1016/j.bone. 2016.05.003 
29. Jääskeläinen T, Itkonen ST, Lundqvist A, Erkkola M, Koskela T, Lakkala K, Dowling KG, Hull GL, Kröger H, Karppinen J, Kyllönen E, Härkänen T, Cashman KD, Männistö S, LambergAllardt C (2017) The positive impact of general vitamin D food fortification policy on vitamin $\mathrm{D}$ status in a representative adult Finnish population: evidence from an 11-y follow-up based on standardized 25-hydroxyvitamin D data. Am J Clin Nutr 105:1512-1520. https://doi.org/10.3945/ajen.116.151415

30. Bulletin of the International Dairy Federation 485/2016, The World Dairy Situation 2016

31. Durup D, Jørgensen HL, Christensen J, Schwarz P, Heegaard AM, Lind B (2012) A reverse J-shaped association of all-cause mortality with serum 25-hydroxyvitamin D in general practice: the CopD study. J Clin Endocrinol Metab 97:2644-2652. https://doi. org/10.1210/jc.2012-1176

32. Madsen CM, Jørgensen HL, Lind B, Ogarrio HW, Riis T, Schwarz P, Duus BR, Lauritzen JB (2012) Secondary hyperparathyroidism and mortality in hip fracture patients compared to a control group from general practice. Injury 43:1052-1057. https://doi.org/10. 1016/j.injury.2011.12.025

33. Lee GH, Lim JW, Park YG, Ha YC (2015) Vitamin D deficiency is highly concomitant but not strong risk factor for mortality in patients aged 50 year and older with hip fracture. J Bone Metab 22:205-209. https://doi.org/10.11005/jbm.2015.22.4.205

34. Holick MF (2009) Vitamin D status: measurement, interpretation and clinical application. Ann Epidemiol 19:73-78. https://doi.org/ 10.1016/j.annepidem.2007.12.001

35. Fakler JK, Grafe A, Dinger J, Josten C, Aust G (2016) Perioperative risk factors in patients with a femoral neck fracture-influence of 25-hydroxyvitamin D and C-reactive protein on postoperative medical complications and 1-year mortality. BMC Musculoskelet Disord 17:51. https://doi.org/10.1186/s12891-016-0906-1

36. Cher EWL, Allen JC, Moo IH, Lo EC, Peh B, Howe TS, Koh JSB (2020) Sub-optimal serum 25-hydroxyvitamin D level affects 2-year survival after hip fracture surgery. J Bone Miner Metab 38:555-562. https://doi.org/10.1007/s00774-019-01082-0
37. Nurmi-Lüthje I, Sund R, Juntunen M, Lüthje P (2011) Post-hip fracture use of prescribed calcium plus vitamin $\mathrm{D}$ or vitamin $\mathrm{D}$ supplements and Antiosteoporotic drugs is associated with lower mortality: a nationwide study in Finland. J Bone Miner Res 26:1845-1853. https://doi.org/10.1002/jbmr.375

38. Hip fracture. Current Care Guideline and summary (2017) Working group appointed by the Finnish Medical Society Duodecim, the Finnish Orthopaedic Association. https://www.kaypahoito.fi/ en/ccs00092 (accessed March 11, 2021)

39. Finnish Food Authority. Vitamin D. (2018) https://www.ruoka virasto.fi/en/themes/healthy-diet/nutrients/vitamin-d/ (accessed March 11, 2021)

40. IOF. International Osteoporosis Foundation (2020) Vitamin D. https://www.osteoporosis.foundation/educational-hub/topic/vitam in-d (accessed April 17, 2021)

41. Dawson-Hughes B, Heaney RP, Holick MF, Meunier PJ, Vieth R (2005) Estimates of optimal vitamin D status. Osteoporos Int 16:713-716. https://doi.org/10.1007/s00198-005-1867-7

42. Lüthje P, Nurmi-Lüthje I, Tavast N, Villikka A, Kataja M (2021) Evaluation of minimal Fracture Liaison Service resource: costs and survival in secondary fracture prevention - a prospective one-year study in South-Finland. Aging Clin Exp Res. https://doi. org/10.1007/s40520-021-01826-x

43. Pekonen SR, Kopra J, Kröger H, Rikkonen T, Sund R (2021) Regional and gender-specific analyses give new perspectives for secular trend in hip fracture incidence. Osteoporos Int. https://doi. org/10.1007/s00198-021-05906-6

Publisher's note Springer Nature remains neutral with regard to jurisdictional claims in published maps and institutional affiliations. 